\title{
Façade Optimization in a Wind-Driven Ventilated Residential Building Targeting Thermal Comfort, IAQ and Energy Consumption
}

\author{
S. Marzban, L. Ding, V. Timchenko, and M. Irger
}

\begin{abstract}
Residential buildings are responsible for a significant percentage of energy use and a huge amount of this energy is used for heating and cooling. Efficient natural ventilation is known as method to reduce the cooling energy use. Almost all of the building in modern cities can only use single-sided natural ventilation and façade design is known as an effective factor in wind driven single-sided ventilation of modern buildings. This research aims to develop a methodology to optimize façade design options in order to gain enough single-sided natural ventilation for a residential block. By means of wind-driven single-sided ventilation we are going to gain our three performance objectives which are thermal comfort and indoor air quality for the occupants and minimizing cooling energy consumption. To achieve this, an integration of genetic algorithm (GA), artificial neural network (ANN) and computational fluid dynamics (CFD) is proposed.
\end{abstract}

Index Terms-Façade, genetic algorithm, optimization, ventilation.

\section{INTRODUCTION}

Residential buildings are responsible for a significant percentage of energy use. Of the energy used in residential buildings, 38\% is used for heating and cooling, making it the largest energy user in homes [1]. This statistic shows that energy consumption for the residential sector is associated with the need to provide thermal comfort and health for the occupants [1].

This leads to the conclusion that a more sustainable approach with using renewable energy sources is needed to provide indoor thermal comfort in residential buildings. To gain this goal, one approach is to improve the ventilation performance of buildings to avoid mechanical cooling systems [1].

As the dense modern cities have buildings with just one façade, single-sided ventilation (SSV) is focused in this research. Previous researches suggest that ventilation performance of a wind-driven SSV room can be significantly improved with appropriate facade treatments such as the

Manuscript received April 12, 2015; revised July 20, 2015. This work was supported by the University of New South Wales under the UIPA scholarship.

Samin Marzban and Lan Din are with the Faculty of Built Environment, University of New South Wales, Sydney, Australia (e-mail: s.marzban@unsw.edu.au).

Victoria Timchenko is with the School of Mechanical and Manufacturing Engineering at the University of New South Wales, Australia (e-mail: v.timchenko@unsw.edu.au).

Matthias Irger is with the Australian School of Architecture and Design, University of New South Wales, Australia (e-mail: m.irger@unsw.edu.au). introduction of a vertical or a horizontal protrusion; also the significant role of the windows shape, area, location, size and type is undeniable.

In pursuit of improvement in indoor air quality (IAQ), thermal comfort (TC), and ventilation energy minimization by façade reliefs in residential buildings, it would be necessary to acquire detailed information about the indoor airflow, the pollutant dispersion as well as the temperature variations resulting from different amount of ventilation. As a result, making use of a computer-based modelling and simulation tool is critical. Computational fluid dynamics (CFD) is employed to model and predict the indoor airflow, thermal distribution, $\mathrm{CO}_{2}$ concentration in this research.

The performance objectives set in this research are: energy consumption, indoor thermal comfort and indoor air quality, which are three very fundamental yet conflicting objectives of building design. Finding a design that takes full advantage of a situation, while satisfies all of these objectives, is a challenge due to the number of parameters and strategies involved. While the classical rules of trial-and-error processes may be able to generate acceptable solutions, it is hard to achieve near optimal designs. In order to significantly reduce the energy consumption while maintaining a comfortable indoor environment, global optimization techniques such as Genetic Algorithm (GA) can be used [2].

This investigation focuses on some different façade reliefs to find the best set of solutions for making use of natural ventilation in order to provide thermal comfort and IAQ for the occupants on one hand, and minimize cooling energy consumption on the other hand. To meet the three performance objectives, it is necessary to employ a highly resolved approach to the problem domain. As discussed above, the ventilation performance in a residential space is highly dependent on a variety of factors which are related to façade design [2]. Consequently, a flexible modelling method has to be used to test a large number of design options. In addition, since building problems are too complicated to be defined as single objective and there would be controversial objectives to deal with in many cases, and as the objective function of such an optimization problem is a nonlinear one, care should be taken to select an appropriate optimization algorithm fitting into the context.

The current study is targeted at addressing such needs by devising and developing an optimization approach: an indoor airflow investigation so as to capture the distribution of assessment indices pertaining to thermal comfort, IAQ, and energy use. It should offer flexibility to predict, evaluate, and compare a wide range of objectives and constraints. 
A Genetic Algorithm (GA) method is proposed to take the advantages of an evolutionary optimization algorithm. A set of optimal design solutions will be derived through an evolutionary approach, while CFD will be used to evaluate ventilation and thermal performance of designs during the evolutionary process. Because it takes an infinite time to predict the performance of a large number of designs using CFD, the Artificial Neural Network is proposed to find the hidden relationship between variables and performance outcomes of designs. By adding the Artificial Neural Network (ANN) into the GA process, a significant amount of time will be saved to get the end set of optimal design solutions.

To summarize, this research will develop an evolutionary model to optimize façade design (focused on windows and vertical louvres) in order to achieve high performance outcomes in thermal comfort and indoor air quality (IAQ) and reduction of the cooling energy consumption. The evolutionary model will be developed using Genetic Algorithm (GA) with the integration of the Computational Fluid Dynamics (CFD) and Artificial Neural Network (ANN) This paper is a part of a $\mathrm{PhD}$ research which is under progress.

\section{OPTIMIZATION ALGORITHMS}

As discussed in the previous section, the whole design space would be all of the different combination of façade variables in different buildings. Due to the large number of façade design options and consequently the large searching space and also the multi-objective nature of the research problem, achieving optimum façade design to meet the performance objectives is so challenging.

Using multi-objective optimization algorithm helps to search the design space and find the design options that meet the performance objectives.

Even using optimization tools though, the handling of multiple objectives remains complex. In general there are two approaches to multiple-objective optimization. One is to combine the individual objective functions into a single composite function [3]-[5]. These methods are based on mathematical procedures and suffers from being dependent on initial guess. [6] Moreover, these techniques can only be applied to smooth and continuous functions. Since building phenomena are very often nonlinear, which lead to discontinuous output [7].

The second general approach is to determine an entire Pareto optimal solution set or a representative subset. A Pareto optimal set is a set of solutions that are non-dominated with respect to each other. While moving from one Pareto solution to another, there is always a certain amount of sacrifice in one objective to achieve a certain amount of gain in the other. Pareto optimal solution sets are often preferred to single solutions because they can be practical when considering real-life problems, since the final solution of the decision maker is always a trade-off between crucial parameters [3].

\section{Genetic AlgORITHM}

The most well-known and widely accepted multi-objective algorithm is Genetic Algorithm (GA), developed by Holland
[8] in the 1970s.

This optimization algorithm, inspired from Darwin's theory of natural selection, has been successfully applied in building studies. In those studies, GAs proved to be very efficient and enabled significant improvements in the optimization result in comparison with the baseline situation.

In a genetic algorithm, a population of candidate solutions (called individuals, or phenotypes) to an optimization problem is evolved through the process. Each candidate solution has a set of properties (its genes) which can be altered through evolution. The evolution starts from a random population of individuals, called a generation. In each generation, the fitness of every individual in the population is evaluated. Fitness is the measurement of the design performance, as energy consumption, IAQ and thermal comfort in this research. Fitness values or scores refer to the value of the performances, and they can be constructed hierarchically. Each individual is evaluated against the fitness and obtains a score. According to the fitness function score the most efficient individuals remain in the process and the inefficient individual are deleted. The new generation of solutions is then created with the remaining individuals. Two random pairs are chosen to create two new individuals, called off springs. This process is called crossover. Each individual can be subjected to a mutation with a small random probability. This is called mutation.

The evolutionary process may be repeated hundreds of times to gain the end result. Commonly, the algorithm terminates when satisfactory fitness level has been reached for the population and a set of optimal solutions is gained. In Fig. 1 a simple diagram of a GA process is shown.

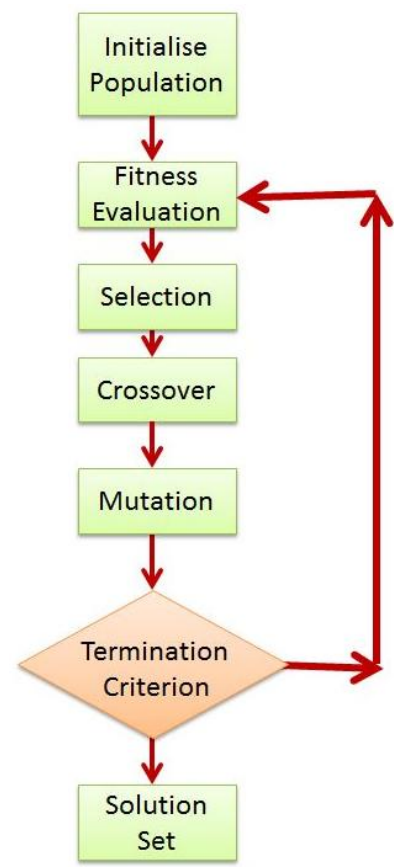

Fig. 1. A schematic GA process.

\section{INTEGRATION OF GA, CFD AND ANN}

In order to find out to what extent each individual meets the fitness function; we should evaluate the individuals in each step. The appropriate evaluation tool for this research is the computational fluid dynamics (CFD). CFD techniques have 
been widely used in research to predict detailed room airflow patterns, highly resolved temperature distributions, and pollutant transportation in indoor environment; hence it is employed to assess thermal comfort, air quality and cooling energy consumption of the design population in this research.

In contrast to physical measurements, the CFD method is relatively inexpensive, is applicable to any existing or conceived scenario, and can provide complete information. Consequently, the optimization approach in this study is to use CFD techniques to evaluate various facade design configurations and operation states against the fitness of thermal comfort, indoor air quality and cooling energy consumption to find the optimal set of solutions.

Since in each step, we need to simulate a large number of building façade designs, the Artificial Neural Network (ANN) is used to reduce the running time of the evaluation process. An ANN is a way to find the hidden relationship between input and output. In this research the input is different configuration of façade and the output is the indices for thermal comfort, indoor air quality and energy consumption. ANN finds the hidden relationship between these input and output in the form of a complicated algorithm. Fig. 2 shows a schematic diagram of the input, output and the hidden layers in an ANN. Hence, ANN can be used in conjunction with $\mathrm{CFD}$ in the evaluation process.

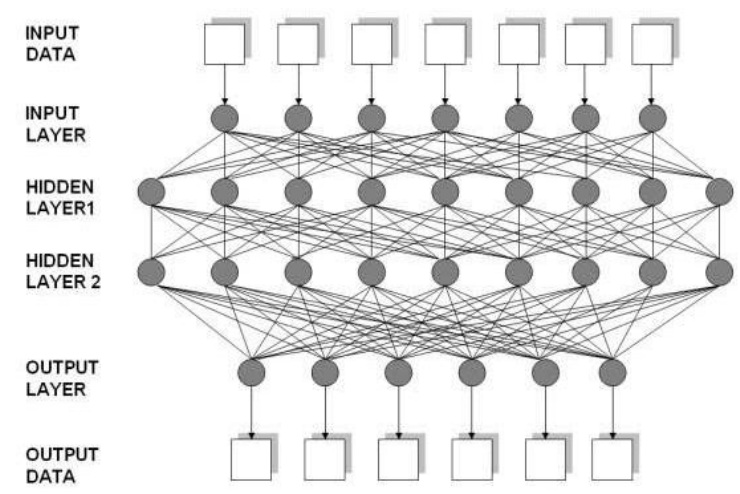

Fig. 1. Input, output and hidden layers in an ANN.

\section{PERformance OBJeCtives As FITNESS FunCtions}

It was explained that in a GA process the individuals need to be evaluated in order to find to what extent they meet the fitness functions. In this step a score is given to each individual to evaluate their fitness, and the individuals which are inefficient and poor would be deleted from the GA loop. The efficient individuals with higher fitness functions will be used as the parents for the next generation of individuals.

In this research, 3 performance objectives are used as fitness functions of the individuals. These three performance objectives are: thermal comfort, indoor air quality and energy consumption. In the evaluation step, an individual will be put into the algorithm derived from the artificial neural network. The output would be 3 performance results for thermal comfort, indoor air quality and energy indices, all of which should be in the given range for the indices. It means that for each the performance objectives up and low constraints are defined and the result should be in these constraints. A reasonable solution to a multi-objective problem is to investigate a set of solutions, each of which satisfies the objectives at an acceptable level without being dominated by any other solution [3].

The fitness functions are evaluated based on the PMV model for thermal comfort, the indoor air quality assessment, and the cooling energy load prediction. The PMV model [9] is the most frequently used and best understood model for quantitative thermal comfort analysis. PMV reflects the mean vote of a large group of occupants who are exposed to a given combination of thermal parameters. PMV index evaluates thermal environment in an indoor space by using a thermal sensation range scale:_3 (cold),_2 (cool),_1 (slightly cool), 0 (neutral), +1 (slightly warm),+2 (warm), +3 (hot) [2]. PMV is defined as a function of six thermal variables related to the indoor air conditions and human behaviors, including air temperature, air humidity, air velocity, mean radiant temperature, clothing insulation level, and human activity [2]. The optimizer attempted to pull the PMV value in adjacent to the occupant closer to neutral value.

The calculated $\mathrm{CO}_{2}$ concentration distribution is used as an index for indoor air quality further integrated into a dimensionless index -ventilation effectiveness - for indoor air quality (IAQ) assessment. Ventilation effectiveness is calculated from an equation which is slightly different from the original definition [2], [10]. The $\mathrm{CO}_{2}$ concentration at breathing level is used here instead of the average concentration throughout the workstation.

The transportation of $\mathrm{CO}_{2}$ in room air will be predicted by the CFD simulations. Furthermore, the optimizer intended to search to decrease the $\mathrm{CO}_{2}$ concentration at breathing level and improve ventilation effectiveness as much as possible.

CFD simulation has been widely used for the prediction of airflow in residential environment; in contrast, issues with regards to heat transfer and energy usage in residential spaces have not been successfully addressed using CFD techniques. The current study will measure the cooling energy consumption that can be derived from the CFD estimations.

\section{FAÇADE FEATURE VARIABLES (WindOWS AND BLADES)}

The building envelope remains one of the most important exterior elements for building ventilation functionality. While the façade is an elegant component that helps to define the unique architectural aesthetics of the building, it also has the critical role related to energy performance and specially cooling energy consumption of the buildings. Various façade relief strategies, such as wing walls, louvres, overhangs and balconies, have been used for various purposes in building design, including such as aesthetics, functionality, climate and local guidelines.

As mentioned previously, in this research façade design variables are related to the variables which have a significant impact on changing the pressure zones and consequently the airflow patterns near the building envelope. These features have significant effects on the air flow pattern near a building. As the consequence of changing the airflow patterns near a building (façade), the patterns inside the building would also change. Table I shows an example of façade feature variables and their constraints.

The variables to be optimized are related to façade features, so it is not possible to consider wind direction and velocity as 
variables in the GA loop. It is assumed that wind is blowing from a particular direction with a defined velocity. The most probable direction and velocity are defined by a wind rose in each region. Since one objective is minimizing cooling energy consumption, the prevailing wind overlay in summer will be considered in the simulation.

\section{GENETIC DESCRIPTION OF FAÇADE DESIGN OPTIONS}

Each feature of the variables of façade design which is supposed to have impact on the three performance outcomes is chosen to be a gene in the GA process. The individuals are made up of these genes, so each building is an individual with a number of genes and each gene is responsible for one feature of façade design.

Encoding of chromosomes is the first question to ask when starting to solve a problem with GA. Encoding depends on the problem heavily. There are four different types of encoding: binary encoding, permutation encoding, value and tree encoding.

Since each chromosome in this research is a sequence of values, the most appropriate encoding method is the value encoding. For the example that is covered in this research the values for the genes would be as Table I. In this example all values are proposed to be real numbers.

GA produces an initial population by taking random values from genes and combining them. After the evaluation process some individuals remained because of good fitness functions. Fig. 3 shows an example of the two individuals. A random cross over point is chosen and two new off springs are created which inherited a part of their properties from chromosome A and a part of their properties form chromosome B. Each of these individuals presents a façade design with a random combination of façade features.

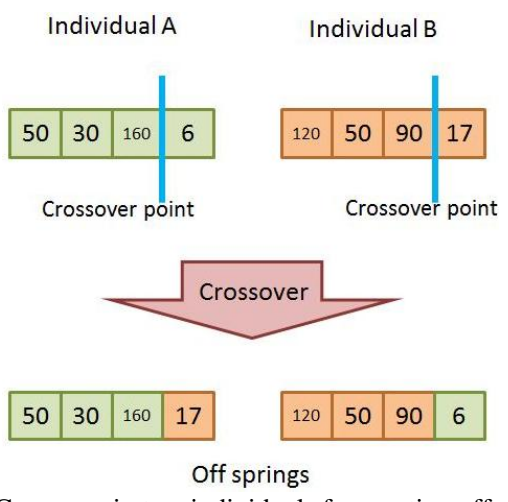

Fig. 3. Crossover in two individuals for creating off springs.

\section{FRAMEWORK OF THE OPTIMIZATION MODEL}

As mentioned above, building problems are too complicated to be defined as single objective. In many cases, there could be conflicting objectives, e.g. high thermal comfort and low energy consumption. This research is targeted at addressing such needs by devising and developing an multi-objective optimization approach: an indoor airflow investigation so as to capture the distribution of assessment indices pertaining to thermal comfort, IAQ, and energy use for a single-sided ventilated residential apartment.

In the particular GA developed for this research each of the façade designs which has a random combination of variables is called an individual or a phenotype. These individuals are made up of genes. So in this research the individuals or phenotypes are façade designs, and the facade features are genes. Each gene controls one characteristic of a façade feature. For example, an individual (façade design) may have four genes. Gene number 1 controls the width of a window. Gene number 2 controls the length of vertical louvres. Genes number 3 and 4 control angle of louvres and the ratio of the window width to the louvre length respectively.

Fig. 4 shows a GA process using CFD for the evaluation of fitness functions. In the first step a number of individuals (façade designs with different combinations of façade features) will be generated randomly.

We can use Matlab software to create the first generation. In the next step CFD will be run to evaluate the individuals against defined fitness functions. It means that by CFD we can check to what extent the individuals meet the performance objectives. The individuals mapping onto fitness functions will be selected as the parents for production of the next generation. These steps are repeated hundreds of generation to find an optimal set of solutions. GA would not reach just one particular answer to the defined problem. It would find a number of optimal solutions called an optimal set.

TABLE I: AN EXAMPLE OF FAÇADE FEARURE VARIABLES AND THEIR

\begin{tabular}{|l|l|l|}
\hline \multicolumn{2}{|l|}{ CONSTRATS } & unit \\
\hline Wenes & Values & $\mathrm{cm}$ \\
\hline $\begin{array}{l}\text { L: length of the vertical } \\
\text { louvers }\end{array}$ & $50,80,100,120,150,200$ & $\mathrm{Cm}$ \\
\hline $\begin{array}{l}\text { A: angle of the vertical } \\
\text { louvers }\end{array}$ & $10,20,30,40,50$ & Degree \\
\hline $\begin{array}{l}\text { W/R: width (of the window) } \\
\text { to length (of the louver) ratio, } \\
\text { it defines the number of } \\
\text { louvers in front of a window }\end{array}$ & $1,2,3, \ldots, 20$ & - \\
\hline
\end{tabular}

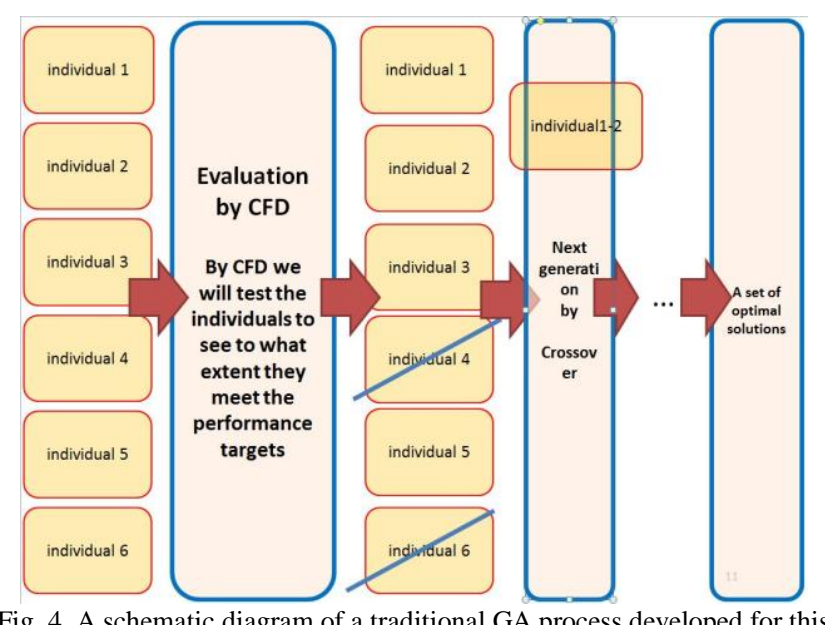

Fig. 4. A schematic diagram of a traditional GA process developed for this research, evaluation is done by CFD.

To show the largeness of the GA loop in this problem, you may imagine the GA setup of 25 individuals in each generation and 50 generation limit, 1250 runs of the CFD program could have been required for a GA search. Therefore, it is prohibitively expensive to directly invoke CFD simulation inside the optimization loop for fitness evaluation. One possible solution to this problem is training an Artificial Neural Network (ANN) to evaluate the individuals in the GA 
loop. In this case the evaluation of the individuals will be done by ANN in conjunction with CFD. Fig. 5 shows the proposed GA process that combines ANN and CFD for the evaluation of fitness functions. The proposed process includes the following three steps:

Step 1: Evaluate fitness functions of a subset of population using CFD;

Step 2: Train and test an ANN model based on the CFD outcomes to obtain the mappings between input and output data;

Step 3: Evaluate fitness functions of the remaining set of population using ANN, and optimize façade designs through the proposed GA process.

Step 1 performs sufficient CFD simulations to predict the performance outcomes in response to the variations in the input data. This part of work can be considered the ANN training/test data preparation by varying the influential variables in the CFD models.

In this step several numbers of combinations of façade features for a single-sided ventilated apartment will be randomly chosen from the whole design space by Matlab software and modelled by CFD (Fig. 4). The façade features include:

$\mathrm{W}$ : width of the window

$\mathrm{L}$ : length of the vertical louvers

A: angle of the vertical louvers

W/L: width (of the window) to length (of the louver) ratio, it defines the number of louvers in front of a window

Step 2 is to train and test an ANN model for quick response approximation by exploiting the input/output data pairs obtained from the CFD simulation. This model can be used in the place of CFD simulation in the fitness evaluation process to reduce the running time.

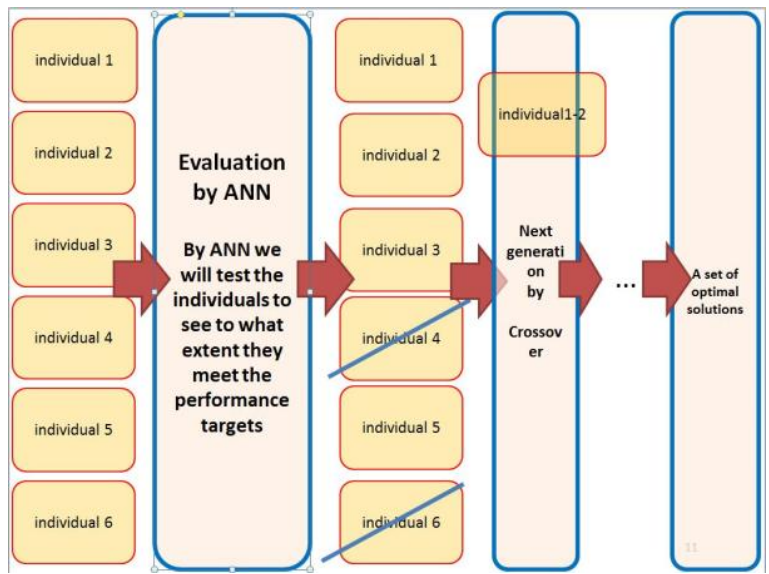

Fig. 5. A schematic diagram of GA process developed for this research, evaluation is done by ANN.

In the ANN training, the façade variables will be used as input data, and thermal comfort (PMV index), indoor air quality (IAQ) and cooling energy consumption as output data. The fitness evaluation of a subset of population will be done by CFD. After obtaining a large number of outputs and input data from the CFD, the ANN will be trained to predict the outputs according the inputs without running the CFD. In order to find out whether the ANN is working properly or not, a number of input data will be tested by the ANN. If the output of the ANN is near to the output of the CFD simulation to a great extent, the ANN has been trained properly. If the errors are not negligible, more data is needed to train the ANN.

Step 3 is to evaluate fitness functions of the remaining set of population using ANN and apply the proposed GA process to search for the near-optimal set of controlled variables in a residential block with particular geometrical configuration, with the goal of achieving satisfactory comfort and IAQ and minimizing the cooling energy consumption. The proposed GA process will run a number of generations to reach the optimal set of results.

\section{ACKNOWLEDGMENT}

This thesis was made possible by the University's International Postgraduate Scholarship (UIPA). I am grateful to the University of New South Wales for the scholarship which enabled me to undertake a $\mathrm{PhD}$ program.

\section{REFERENCES}

[1] M. F. Mohamed, "The potential of balconies to induce wind-driven natural ventilation in single-sided ventilated high-rise apartments,' 2011, University of New South Wales, Built Environment.

[2] L. Zhou and F. Haghighat, "Optimization of ventilation system design and operation in office environment," Part I: Methodology, Building and Environment, vol. 44, no. 4, pp. 651-656, 2009.

[3] A. Konak et al., "Multi-objective optimization using genetic algorithms: A tutorial," Reliab. Eng. Syst. Saf., vol. 91, no. 9, pp. 992-1007, 2006.

[4] L. Magnier et al., "Multiobjective optimization of building design using TRNSYS simulations, genetic algorithm, and artificial neural network," Building and Environment, vol. 45, no. 3, pp. 739-746, 2010.

[5] J.-H. Huh and M. J. Brandemuehl, "Optimization of air-conditioning system operating strategies for hot and humid climates," Energy and Buildings, vol. 40, no. 7, pp. 1202-1213, 2008.

[6] K. Deb and D. Kalyanmoy, Multi-Objective Optimization Using Evolutionary Algorithms, p. 518, 2001.

[7] M. Wetter and J. Wright, "A comparison of deterministic and probabilistic optimization algorithms for nonsmooth simulation-based optimization," Building and Environment, vol. 39, no. 8, pp. 989-999, 2004.

[8] J. H. Holland, "Adaptation in natural and artificial systems: an introductory analysis with applications to biology, control, and artificial intelligence," University of Michigan Press, 1975.

[9] P. O. Fanger, Thermal Comfort: Analysis and Applications in Environmental Engineering, Danish Technical Press, 1970.

[10] H. B. Awbi, Ventilation of Buildings, London; New York: E \& FN Spon, 1991.

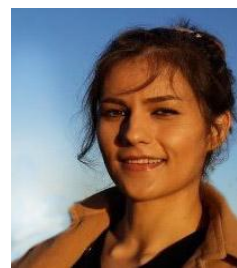

Samin Marzban completed her master of science in architectural engineering at the Iran University of Science and Technology in 2010. Prior to her master, she completed the bachelor of science in Imam Khomeini International University, Iran. After completing her master, she held the position of a lecturer in some colleges and universities in Iran.

She is a $\mathrm{PhD}$ candidate at the Faculty of Built Environment, University of New South Wales, Sydney, Australia. Her current area of research is façade optimization in residential buildings.

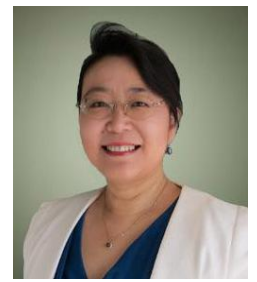

Lan Ding received her $\mathrm{PhD}$ at the University of Sydney's Faculty of Architecture, Design and Planning. Prior to joining the Faculty of Built Environment at UNSW, Lan held the position of a senior research scientist at CSIRO (2000-2011) and senior lecturer at the Sustainable Buildings Research Centre at the University of Wollongong (2011-September 2013).

Dr Lan Ding has over 10 years research experience in sustainable buildings and cities, building and urban information modelling, multi-agent simulation, GIS, integration of smart grid with smart buildings and cities, energy efficiency and climate adaptation, life cycle assessment, as well as the application of artificial intelligence to built and urban environments. 
Lan has won various awards for research innovation and leadership, including national and state awards from the Australian Institute of Building, the Fresh Innovators Award and the CSIRO Divisional Award for excellence in a successful project providing an invaluable information resource to help the land development industry create more sustainable neighbourhoods.

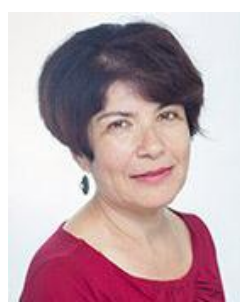

V. Timchenko is a senior lecturer in the School of Mechanical and Manufacturing Engineering at the University of New South Wales. She completed her honours degree in physics at Kharkov State University, Ukraine, and her $\mathrm{PhD}$ in Engineering (1993) at the Institute for Problems in Machinery, the Ukrainian Academy of Sciences. Her areas of expertise are computational fluid dynamics and heat transfer. Her research interests include natural convection and phase change problems; cooling of building integrated photovoltaic systems and microelectronic devices; synthetic jets; modeling of nano-particles in human arteries and laser hyperthermia for biomedical applications

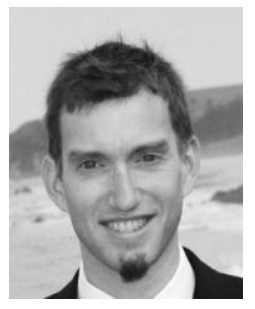

Matthias Irger is an architect, urbanist and academic, who has specialised in sustainable design. $\mathrm{He}$ is a lecturer at the Australian School of Architecture and Design, University of New South Wales, with an applied research interest in improving the heat resilience of cities.

Matthias completed his $\mathrm{PhD}$ program in sustainable urbanism at the Australian Graduate School of Urbanism, University of New South Wales. His areas of expertise are high-rise and transport architecture, climate-sensitive urban design and planning, urban heat mitigation, climate change adaptation, low-carbon and healthy communities, and spatial data analysis.

Dr Matthias Irger is a German and educated architect and urbanist, who has specialised in applied sustainable design. He has managed the successful delivery of award-winning projects recognized for their design excellence and innovation from concept stage to completion, leading large, interdisciplinary design and documentation teams in complex and challenging environments. 